\title{
Política y Sociedad
}

ISSN: $1130-8001$

ISSN-e: 1988-3129

Oliván López, F. (2017): Antropología de las formas políticas de Occidente, Madrid, Escolar y Mayo Editores, 346 pp.

La obra aquí presentada es la segunda parte de un largo proyecto científico, de muy profundo alcance, sobre la reconstrucción del ordenamiento político de nuestro entorno cultural. Un trabajo de investigación iniciado por el autor mediante la publicación de los primeros resultados en el volumen titulado Nueva teoría política en el año 2015. Ensayo sobre el que el profesor Gabriel Albiac nos advertía:

Construir un libro de teoría política sin una sola nota a pie de página implica un envite muy alto. Tanto más si se trata — tal es el caso — de una obra de talante y estructura inequívocamente académica... Asombrosamente, el libro funciona (...) y el lector acaba su lectura con la certeza de habérselas visto con una obra sólida, con una obra que posee vida propia (Albiac, 2015)

Confirmados plenamente los planteamientos enunciados, este libro se presenta, también, como "un envite muy alto", ya que vuelve a romper las exigencias y moldes de los clásicos trabajos de teoría política, y pese a ello, consigue mantener ese "talante y estructura inequívocamente académica".

Con este segundo tomo, nos encontramos ante un libro dispuesto a vagar entre la filosofía y la teoría política. Cuestión afrontada desde una perspectiva dada a la combinación de la erudición con planteamientos atrevidos y rupturistas. El propio autor lo reconoce tanto en esa nota introductoria como en la nota bibliográfica al final del volumen, que aconsejo leer en primera instancia. Nadie debe esperar, aquí, un mero catálogo, más o menos ordenado, de las obras consultadas. La nota apunta a mucho más, según es señalado; estamos ante la expresión de la pretensión ultima del libro: una pieza en la "semiosfera" (Bajtin, 2011) en la cual circula el mundo del pensamiento, ese caldo de cultivo imprescindible para la creación de los mejores ensayos. Un espacio o margen compañero del trabajo, gracias al cual tal labor se hace posible.

La otra clave de lectura aparece al inicio de la nota de apertura de este libro, verdadera declaración de intenciones, soporte fundamental en la edificación de esta disertación: 
Nos proponemos una osadía: mirar el hecho político desde el ser animal de nuestra identidad humana. Por eso no nos sirven las propuestas de una ciencia política, demasiado tributaria de la dictadura del humanismo. Sin embargo, compensamos nuestra osadía con la humildad de nuestras premisas: la mirada ingenua sobre los meros detalles. Continuamos así el viaje que emprendimos con Nueva teoría política, donde empezamos la serie radical de nuestras preguntas. Viaje fundacional del que este tomo se vindica como segunda etapa (Oliván, 2017).

Por otra parte, resulta importante, también, detenernos un momento sobre las formas. La primera ruptura respecto a los modelos académicos actuales se percibe en el talante de este texto. "El estilo es la vida", dijo un gran historiador reclamando la expresión como parte integrante de un trabajo científico. En este efecto, Oliván reafirma esta idea y hace de estos aspectos formales una parte integrante del libro. La condición de científico no solo no debe estar reñida con esta dimensión formal y estética, ha de ser percibida, además, como instrumento fundamental para la trasmisión de los conocimientos alcanzados. Estamos ante una producción disciplinar donde el estilo es una parte esencial de su aportación académica. De este tratamiento poético de los símbolos, de las lecturas literarias y del marco mítico, resulta el mejor instrumento para introducirnos en ese universo de ideas al que nos conduce esta innovadora aportación.

La segunda ruptura radica en los recursos utilizados para centrar la atención en el análisis teórico. Con el mismo repaso de alguno de los enunciados nos da las ideas claves del deambular del entendimiento del quehacer politológico: poética, dramaturgia y estética. La obra profundiza en todos estos factores del mundo analizándolos, además, desde esa perspectiva cimentada desde el mismo lenguaje. Forma y contenido alcanzan, así, una unidad muy diferenciada de las formas más recurrentes de los trabajos desarrollados al uso. Y con ello avanzamos sobre otra de las características de la obra, la metodología empleada. Como sucedía en Nueva teoría política, en esta ocasión entra sin complejo alguno en campos disciplinares muy diversos, desde la teoría literaria al análisis religioso y a la teología en su definición más clásica (Oliván, 2015). En todo ello, claro está, la participación del ejercicio hermenéutico del psicoanálisis no ha quedado fuera de lugar. Allí, tanto fuentes como métodos no solo resultan plurales, sino que combinan con rigor, coherencia y ritmo.

Respecto a los contenidos no debemos olvidar algunas cuestiones importantes, surgidas en la difusión del escrito en estas líneas reseñado. Los primeros observadores apuntan que "Estamos ante un vendaval de ideas" muy poco frecuente, dotado de gran capacidad para terminar descolocándonos de las seguridades donde se asienta el saber académico. Una obra con capacidad de arrastrarnos a pensar desde fuera de los lugares comunes, abriendo en canal principios axiomáticos de nuestro entendimiento y dominio académico. En definitiva, estamos ante un verdadero proyecto fundacional, iniciado con el volumen precedente Nueva teoría política, que posiblemente se cierre en una trilogía. Con ello, se funda una nueva forma de pensar el espacio políticocultural dentro del marco de la vida del ser humano. Un proyecto inclinado a reafirmarse como la búsqueda de un entender los objetos (o aparatos, como más de una vez los califica el autor) sobre los que gravita la condición específica de 
nuestra especie, definida ya como humana. En este efecto, Oliván (2017) designa los considerados como principales: la religión, el arte, la política, el derecho, la economía y la lengua, entre otros. Todos ellos contemplados como subestructuras de una realidad abarcadora y constituyente del modelo central de ese proceso evolutivo muy distante del resto de especies de la clase "homo": el lenguaje.

Así, todos estos aparatos aludidos por el autor: economía, derecho, política... son solo entendidos como campos específicos del lenguaje; conjunto de estructuras simbólicas, definidoras de nuestra identidad. Asuntos principales en la gravitación de la tensión evolutiva que nos llevó a desprendernos de las otras ramas zoológicas. Cuestión central, al parecer, del próximo volumen. Sobre ello, se centrará entonces en ese proceso tensional que arrastró a la constitución de esa identidad como ser biológico. El tomo actual se centra sobre uno de esos otros aspectos de las señas de humanidad: la política.

Esta identidad entre política y lenguaje nos resulta fundamental para comprender la obra. La idea central está dirigida a reinstaurar eso que el propio Fernando Oliván denomina "el acontecimiento político como pura manifestación del lenguaje". Alcanzar este punto entraña dos pasos más o menos sucesivos. Por un lado, reclama recrear la teoría del poder político desde su dimensión comunicativa, de ahí esa magnífica intuición de los flujos del poder vinculados a la lingüística del poder y, por otro, articular el espacio de funcionamiento de la política en las dimensiones donde esa voz se hace reconocible. El creador de estas reflexiones resuelve las exigencias impuestas por estas dos premisas, en el marco de una institución elevada por él a paradigma fundacional de la idea política: el teatro. El magistral conocimiento del autor sobre el arte dramático clásico le permite desarrollar toda una serie de ejemplos, modelos e interpretaciones útiles para convertir el libro, sobre todo en esta parte, en un diálogo literario de alto voltaje. Según avanza en sus argumentaciones, la incorporación del elemento lúdico, el goce festivo, la savia del deseo enmarcaran esas líneas de investigación próxima a desarrollar en la culminación de la trilogía.

La segunda parte del libro orienta su mirada hacia la actualidad contemporánea. El Estado, la sociedad civil, la deriva del capitalismo actual, la idea de bienestar como objetivo de la acción política nos sirven para apreciar que todo este análisis no queda, en absoluto, en los viejos estratos arqueológicos donde fructificaron los mitos clásicos. Al contrario, esa radicalización de la modernidad del transcurso de nuestra vida sigue articulada bajo esos mismos enunciados y formas de entender. En definitiva, la política como lenguaje, teatro, flujo de signos siempre desarrollada en el escenario de la interlocución, no ha cambiado desde la constitución de aquellas antiquísimas hordas emergentes en nuestro pensamiento, cuando nos remitimos al hombre primitivo. De aquel mundo apenas nos separan esas meras sombras - todas las referidas en la nota introductoria - del saber ideológico. Eso sí, unas sombras tan fuertes que, remedando el discurso del Génesis, fueron capaces de transformar ese barro animal de nuestra naturaleza biológica en la realidad actual de nuestra entidad humana. 


\section{Bibliografía}

Albiac, G. (2015): "Pensar lo político", Leer, año XXXI, n 262, Mayo.

Bajtin, M. (2011): Las fronteras del discurso, Madrid, Traficantes de Sueños.

Oliván, F. (2015): Nueva teoría política, Madrid, Escolar y Mayo.

Tomás Pedro Gomariz Acuña

Universidad Rey Juan Carlos, España

tomas.gomariz@urjc.es 